\title{
COMMUNICATION STYLES IN PT XYZ
}

\author{
Shelly Andelline \\ Magister Manajemen, Universitas Tarumanagara Jakarta \\ Email: andellineshelly@gmail.com
}

Masuk : 03-06-2018, revisi: 24-05-2019, diterima untuk diterbitkan : 30-10-2019

\begin{abstract}
ABSTRAK
Mengenal dan memahami gaya komunikasi sangat penting bagi seorang individu untuk mengembangkan keterampilan diri yang optimal. Dengan mengetahui dan memahami gaya komunikasi, seseorang dapat mengetahui kemampuan dan bakat mereka. Mereka akan tahu bagaimana meningkatkan hubungan interpersonal dalam berkomunikasi dalam organisasi. Tujuan dari penelitian ini adalah untuk mengetahui dan menganalisis (a) Apa gaya komunikasi dominan yang digunakan berdasarkan level manajer, level supervisor dan level staf di PT XYZ? (B) Bagaimana meningkatkan hubungan interpersonal pada masing-masing Gaya Komunikasi? Metode yang digunakan dalam penelitian ini adalah dengan menyebarkan kuesioner kepada responden. Alat pengukur dalam bentuk kuesioner adalah skala likert. Sampel yang terlibat dalam penelitian ini adalah karyawan Ho di PT XYZ. Gaya Komunikasi ditentukan oleh seberapa sering kita menggunakan dua elemen penting seperti umpan balik dan pengungkapan. Dalam penelitian ini akan dibahas 4 gaya yang biasanya digunakan dalam komunikasi, yaitu gaya tertutup, gaya buta, gaya tersembunyi dan gaya terbuka. Dari empat gaya komunikasi yang dibahas di atas, tidak ada gaya komunikasi yang baik atau buruk karena masing-masing memiliki sisi positif dan negatif.
\end{abstract}

Kata Kunci: Gaya Komunikasi, Meningkatkan Hubungan Interpersonal

\begin{abstract}
Know and understand communication style is very important for an individual to develop their optimum self-skills. With knowing and understanding the communication style, someone could know their ability and talents. They will know how to improve interpersonal relationships in communicating in the organization. The purpose of this research is to know and analyze (a) What is the dominant communication style used based on manager level, supervisor level and staff level at PT XYZ? (b) How to improve interpersonal relationships on each Communication Style? The method used in this research is by spreading questionnaire to the respondents. Instrument gauges in questionnaire form is likert scale. Sample involves for this research are the Ho employees in PT XYZ. Communication Style specified by how often we use two important element such as feedback and disclosure. In this research will discuss 4 styles usually used in communication, that is closed style, blind style, hidden style and open style. Of the four communication styles discussed above, there is no good or bad communication style because each have the positive and negative side.
\end{abstract}

Keywords : Communication Style, Improving Interpersonal Relationship

\section{PENDAHULUAN}

\section{Latar Belakang}

Dalam menjalankan kehidupan berkelompok atau berorganisasi, manusia selalu aktif untuk melakukan interaksi melalui komunikasi. Menurut Keith Davis (2010) dalam bukunya yang berjudul Human Relation At Work menyatakan bahwa "Communication in the process of passing information and understanding from one person to another". Terjadinya komunikasi adalah sebagai konsekuensi dari hubungan sosial masyarakat yang paling sedikit ada dua orang yang saling berhubungan satu sama lainnya dan menimbulkan sebuah interaksi sosial. Menurut Komala (2009) bahwa Proses Komunikasi terjadi manakala manusia berinteraksi dalam aktivitas komunikasi, menyampaikan pesan dan mewujudkan motif komunikasi. Jika Komunikasi yang terjadi antara karyawan adalah komunikasi yang baik maka akan meningkatkan prestasi kerja sehingga tingkat kinerja suatu organisasi menjadi semakin baik. 
Mengenal dan memahami communication style sendiri sangat penting agar seorang individu dapat mengembangkan diri secara optimal. Ini tidak hanya berlaku bagi keberhasilan di lingkungan kerja melainkan juga di lingkungan kehidupan lainnya termasuk keluarga, sosial dan masyarakat. Dengan mengenal dan memahami communication style sendiri, seseorang dapat mengetahui kemampuan dan bakat-bakatnya serta tahu bagaimana meningkatkan hubungan interpersonal dalam komunikasi di suatu organisasi. Oleh karena itu, dalam penelitian ini akan dibahas berbagai communication style agar individu dapat mengenal diri dan menggali tingkatan yang berbeda dalam pengungkapan diri melalui komunikasi.

\section{Rumusan Masalah}

1. Apa Communication Style yang lebih dominan digunakan berdasarkan level manager, supervisor dan staff di PT XYZ?

2. Bagaimana meningkatkan hubungan interpersonal pada masing-masing Communication Style?

\section{METODE PENELITIAN}

\section{Jenis Data}

Jenis data yang digunakan adalah data primer. Data primer adalah data yang dikumpulkan langsung dari objeknya dan diolah sendiri oleh orang yang melakukan penelitian baik pada suatu organisasi maupun perorangan. Data primer diperoleh dengan cara menyebarkan daftar pertanyaan (kuesioner) kepada responden.

\section{Sumber Data}

Sumber data yang digunakan adalah data internal. Data internal merupakan data yang didapat dari dalam perusahaan/organisasi di mana riset dilakukan. Dalam penelitian ini, data didapat dari PT XYZ.

\section{Metode Pengumpulan Data}

Metode pengumpulan data yang digunakan adalah metode survey dengan teknik kuesioner. Instrumen pengukur dalam bentuk kuesioner ini adalah tipe skala likert. Menurut Sugiyono (2010), "Skala Likert digunakan untuk mengukur sikap, pendapat, dan persepsi seseorang atau sekelompok orang tentang fenomena sosial". Untuk setiap pilihan jawaban diberi skor, maka responden harus memilih angka 1-5 yang mewakili seberapa mencerminkan (5) sampai itdak mencerminkan (1) communication styles di lingkungan kerja.

\section{Objek Penelitian}

Perusahaan yang menjadi objek dalam penelitian ini adalah PT XYZ, salah satu perusahaan pertambangan di Indonesia yang memproduksi dan menyediakan batu bara untuk memenuhi kebutuhan pasar lokal dan global.

\section{Populasi dan Sampel}

Menurut Indriantoro (2009), populasi adalah wilayah generalisasi yang terdiri atas objek dan subjek yang mempunyai kualitas dan karakteristik tertentu yang ditetapkan oleh peneliti untuk dipelajari dan kemudian ditarik kesimpulannya. Populasi yang dipilih dalam penelitian ini adalah karyawan Ho (Pusat) dan karyawan Site (Tambang) di PT XYZ. Sampel adalah bagian dari populasi yang akan diteliti. Sampel dalam penelitian ini adalah karyawan Ho di PT XYZ karena untuk karyawan Site terdapat di Lahat, Palembang sehingga adanya keterbatasan jarak dan waktu.

\section{Alasan Pemilihan Kasus}


Peneliti ingin mengetahui dan menganalisis Communication Style yang terdiri dari Closed Style, Blind Style, Hidden Style dan Open Style yang mana lebih dominan digunakan berdasarkan level manager, supervisor dan staff di PT XYZ. Selain itu, peneliti juga akan membahas cara untuk meningkatkan hubungan interpersonal pada masing-masing Communication Style karena setiap orang harus dapat mengkomunikasikan sesuatu secara efekif dan harus terus menerus belajar untuk meningkatkan kemampuan komunikasinya.

\section{HASIL DAN PEMBAHASAN}

\section{Data Responden}

a) Responden berdasarkan Jenis Kelamin dan Usia

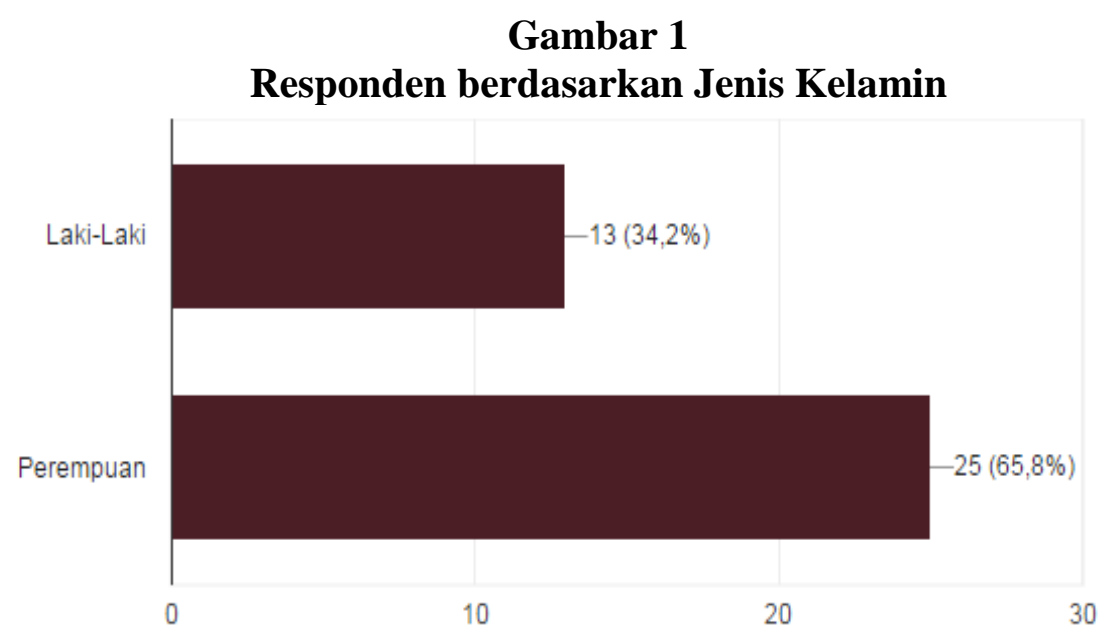

Gambar 2

Responden berdasarkan Usia

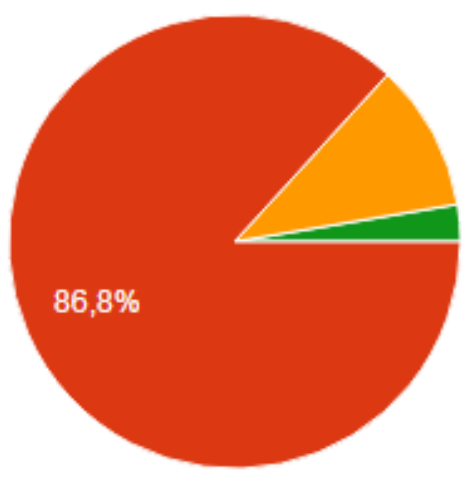

$<20$ tahun

21-30 tahun

31-40 tahun

41-50 tahun

$>51$ tahun

b) Responden berdasarkan Jabatan dan Lama Bekerja

\section{Gambar 3}

\section{Responden berdasarkan Jabatan}




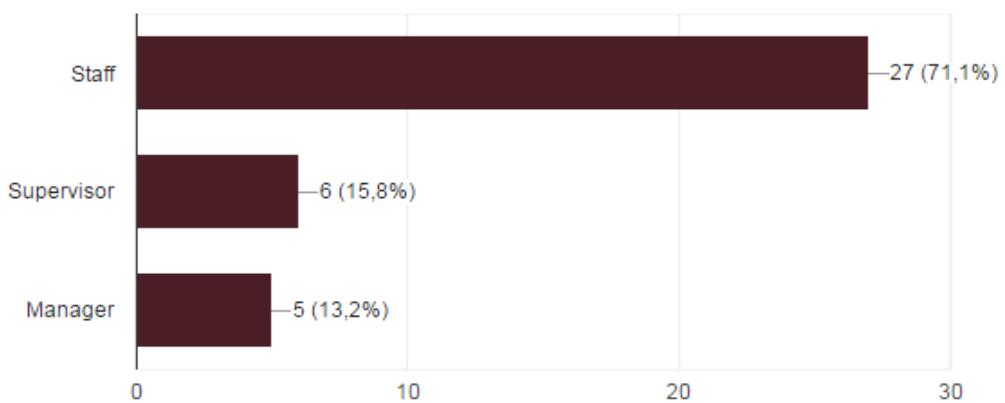

Gambar 4

Responden berdasarkan Lama Bekerja

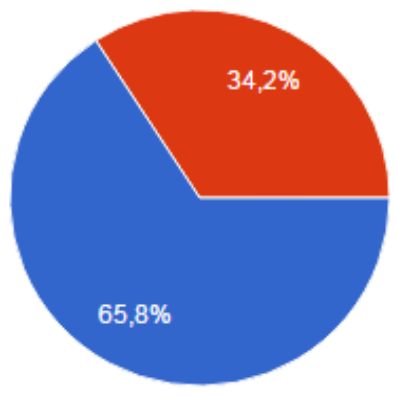

$<5$ tahun

5- 10 tahun

11-15 tahun

$>15$ tahun

\section{ANALISIS}

Berikut adalah score hasil kuesioner dari responden berdasarkan level manager, level supervisor dan level staff di PT XYZ:

a) Score hasil kuesioner dari responden berdasarkan level manager :

Tabel 1

Hasil Kuesioner Level Manager

\begin{tabular}{|c|c|c|c|c|c|}
\hline Jabatan & $\begin{array}{c}\text { Score Closed } \\
\text { Style }\end{array}$ & $\begin{array}{c}\text { Score Blind } \\
\text { Style }\end{array}$ & $\begin{array}{c}\text { Score Hidden } \\
\text { Style }\end{array}$ & $\begin{array}{c}\text { Score } \\
\text { Open } \\
\text { Style }\end{array}$ & Communication Style \\
\hline Manager & 6 & 13 & 10 & 12 & Blind Style \\
\hline Manager & 11 & 14 & 13 & 15 & Open Style \\
\hline Manager & 7 & 8 & 8 & 9 & Open Style \\
\hline Manager & 5 & 13 & 12 & 14 & Open Style \\
\hline Manager & 6 & 14 & 11 & 12 & Blind Style \\
\hline
\end{tabular}

Berdasarkan tabel diatas, bisa kita lihat score hasil kuesioner dari responden dengan level manager pada PT XYZ. Communcation style yang lebih dominan digunakan pada level manager di PT XYZ adalah Open dan Blind Style. Komunikator open style memiliki feedback yang tinggi dan disclosure yang tinggi. Komunikator blind style rendah pada feedback dan tinggi pada disclosure. Level manager di PT XYZ harus bekerja pada tatanan konseptual dan pemikiran bukan lagi pada hal-hal teknis sehingga manager dituntut untuk bekerja dalam team, tertarik pada produktivitas perusahaan, serta dapat menghasilkan solusi yang memuaskan bagi semua kebutuhan pihak. Dimana karakteristik ini merupakan karakteristik dari open style. Selain itu, seorang manager juga harus merupakan orang yang kritis, menuntut dalam pekerjaan, harus mempunyai ide-ide dan mampu mengungkapkannya. Karekteristik ini merupakan karakteristik dari blind style.

b) Score hasil kuesioner dari responden berdasarkan level supervisor : 


\section{Tabel 2}

Hasil Kuesioner Level Supervisor

\begin{tabular}{|c|c|c|c|c|c|}
\hline Jabatan & $\begin{array}{c}\text { Score Closed } \\
\text { Style }\end{array}$ & $\begin{array}{c}\text { Score } \\
\text { Blind Style }\end{array}$ & $\begin{array}{c}\text { Score Hidden } \\
\text { Style }\end{array}$ & $\begin{array}{c}\text { Score } \\
\text { Open Style }\end{array}$ & Communication Style \\
\hline Supervisor & 7 & 13 & 13 & 11 & Blind \& Hidden \\
\hline Supervisor & 7 & 11 & 11 & 11 & Blind, Hidden, Open \\
\hline Supervisor & 6 & 10 & 12 & 13 & Open \\
\hline Supervisor & 8 & 11 & 12 & 15 & Open \\
\hline Supervisor & 7 & 10 & 13 & 14 & Open \\
\hline Supervisor & 8 & 12 & 11 & 10 & Blind \\
\hline
\end{tabular}

Berdasarkan tabel diatas, bisa kita lihat score hasil kuesioner dari responden dengan level supervisor pada PT XYZ. Communcation style yang lebih dominan digunakan pada level supervisor di PT XYZ adalah Open dan Blind Style. Supervisor adalah pekerja yang berhubungan langsung dengan manager. Supervisor mempunyai tugas yang tidak mudah karena memiliki tugas yang strategis dari manager dan harus melakukan hal-hal teknis sekaligus. Terdapat 2 responden dengan level supervisor yang memiliki Hidden Style. Komunikator Hidden Style memiliki feedback yang tinggi dan disclosure yang rendah. Supervisor tipe ini adalah pendengar yang baik, menyukai lingkugan sosial, ingin bersahabat dengan semua orang. Akantetapi ketika tugas rumit diberikan mereka tidak terlalu berhasil.

c) Score hasil kuesioner dari responden berdasarkan level staff :

Tabel 3

Hasil Kuesioner Level Staff

\begin{tabular}{|l|r|r|r|r|l|}
\hline Jabatan & $\begin{array}{c}\text { Score } \\
\text { Closed Style }\end{array}$ & $\begin{array}{c}\text { Score } \\
\text { Blind Style }\end{array}$ & $\begin{array}{l}\text { Score Hidden } \\
\text { Style }\end{array}$ & $\begin{array}{c}\text { Score } \\
\text { Open Style }\end{array}$ & Communication Style \\
\hline Staff & 11 & 13 & 9 & 11 & Blind \\
\hline Staff & 6 & 13 & 12 & 14 & Open \\
\hline Staff & 8 & 11 & 11 & 9 & Blind \& Hidden \\
\hline Staff & 7 & 11 & 13 & 12 & Hidden \\
\hline Staff & 5 & 12 & 12 & 10 & Blind \& Hidden \\
\hline Staff & 11 & 15 & 11 & 10 & Blind \\
\hline Staff & 5 & 7 & 6 & 6 & Blind \\
\hline Staff & 3 & 7 & 8 & 7 & Hidden \\
\hline Staff & 12 & 14 & 12 & 8 & Blind \\
\hline Staff & 9 & 15 & 12 & 14 & Blind \\
\hline Staff & 7 & 10 & 11 & 9 & Hidden \\
\hline Staff & 9 & 9 & 11 & 10 & Hidden \\
\hline Staff & 5 & 12 & 11 & 9 & Blind \\
\hline Staff & 7 & 8 & 12 & 11 & Hidden \\
\hline Staff & 11 & 11 & 11 & 9 & Closed, Blind, Hidden \\
\hline Staff & 6 & 13 & 12 & 12 & Blind \\
\hline Staff & 6 & 9 & 10 & 12 & Open \\
\hline & & & & & \\
\hline
\end{tabular}




\begin{tabular}{|l|r|r|r|r|l|}
\hline Jabatan & $\begin{array}{c}\text { Score } \\
\text { Closed Style }\end{array}$ & $\begin{array}{c}\text { Score } \\
\text { Blind Style }\end{array}$ & $\begin{array}{c}\text { Score Hidden } \\
\text { Style }\end{array}$ & $\begin{array}{c}\text { Score } \\
\text { Open Style }\end{array}$ & Communication Style \\
\hline Staff & 10 & 11 & 12 & 10 & Hidden \\
\hline Staff & 9 & 13 & 11 & 11 & Blind \\
\hline Staff & 11 & 9 & 12 & 12 & Hidden \& Open \\
\hline Staff & 7 & 9 & 14 & 12 & Hidden \\
\hline Staff & 7 & 11 & 7 & 11 & Blind \& Open \\
\hline Staff & 8 & 13 & 8 & 8 & Blind \\
\hline Staff & 8 & 10 & 10 & 11 & Open \\
\hline Staff & 8 & 13 & 11 & 11 & Blind \\
\hline Staff & 8 & 12 & 11 & 13 & Open \\
\hline Staff & 4 & 14 & 12 & 11 & Blind \\
\hline
\end{tabular}

Berdasarkan tabel diatas, bisa kita lihat score hasil kuesioner dari responden dengan level staff pada PT XYZ. Communcation style yang lebih dominan digunakan pada level staff di PT XYZ adalah Blind Style. Jika kita analisis berdasarkan pada teori johari window, blind area merupakan area dimana seseorang tidak mengetahui dirinya sendiri, sementara orang lain di sekitarnya mengetahuinya. Wajar jika para staff di PT XYZ lebih dominan ada di blind area karena mereka masih berada pada di piramida paling bawah di sebuah organisasi dan mempunyai fungsi yang bisa dikatakan terbatas karena setiap pekerjaan pada level ini sudah memiliki pelaksana langsung seperti staff accounting, staff tax, staff finance, staff logistik dan staff HRD. Sehingga para staff mempunyai keterbatasan jika ingin meningkatkan hubungan antar kelompok yang dinamis serta meningkatkan kualitas dan kerjasama tim karena mempunyai fungsi pekerjaan yang terbatas. Terdapat 1 responden dengan level staff yang memiliki Closed Style. Komunikator Closed Style memiliki feedback dan disclosure yang rendah. Tipe orang ini lebih nyaman jika berkerja sendiri, kesulitan dalam mengkomunikasikan ide/gagasan, serta menghindari jika adanya pembuatan keputusan.

\section{Cara meningkatkan hubungan interpersonal pada masing-masing Communication Style}

\section{Closed Style}

Berkomunikasi dengan atasan yang gaya komunikasinya closed style harus berhati-hati, jangan meningkatkan rasa tidak aman dan membuat konflik. Para atasan tipe ini sangat sulit untuk mengkomunikasikan harapan mereka dan merasa tidak nyaman di sekitar orang sehingga mereka sering kecewa dan bahkan mengecewakan orang lain. Akantetapi para atasan seperti ini akan sangat produktif ketika mereka bekerja di lingkungan yang bebas dari tuntutan antarpribadi.

Para bawahan dengan gaya komunikasinya closed style harus terdapat rantai komando yang jelas dan batasi kritik yang bisa membuat kinerjanya menurun. Ketika memberikan instruksi pekerjaan dengan tipe ini harus yang detail/spesifik. Para bawahan dengan tipe ini harus diletakkan ke dalam lingkungan yang aman dan nyaman agar kinerjanya tidak terganggu.

\section{Blind Style}

Belajar dari atasan yang gaya komunikasinya blind style. Para atasan tipe blind style sangat berorientasi tugas. Jika ingin memberikan kritik berilah kritik yang membangun. Penuhi harapan mereka seperti tepat waktu dalam menyelesaikan tugas dan disiplin. Mereka biasanya sangat berpengalaman dan berpengetahuan luas mengenai bidang yang mereka 
kuasai. Karena sikap kritis dan menuntutunya menyebabkan orang lain memandanganya sebagai atasan yang otoriter.

Para bawahan dengan gaya komunikasinya blind style harus diberi kesempatan karena jika mereka tidak diizinkan untuk memberikan feedback, mencoba hal-hal dengan cara mereka, mereka tidak akan dapat mengembangkan potensi mereka. Biasanya bawahan dengan tipe ini sangat setia dan dapat diandalkan, tugas mereka pasti akan selesai.

\section{Hidden Style}

Para atasan dengan tipe hidden style sering menyembunyikan perasaan dan pengetahuan mereka dari orang lain. Mereka adalah orang yang tidak setia dan tidak mempercayai bawahannya sepenuhnya. Para atasan tipe ini hanya mengungkapkan argumen yang postif dan selalu mengindari konflik. Ini akan menjadi sulit dalam hubungan atasan dan bawahan. Karena jika seorang atasan tidak mau berbagi pengetahuan maka bawahan yang pengalamannya terbatas akan sulit dalam pekerjaan. Dan jika mereka hanya menyampaikan argumen positif ini tidak akan membuat suatu organisasi maju dan berkembang.

Para bawahan dengan gaya komunikasinya hidden style adalah orang yang selalu berkata "ya". Pekerjaan mereka akan termotivasi jika terdapat pujian dari lingkungan kerja seperti atasan atau rekan kerja. Para bawahan ini hanya mengekspresikan ide yang hanya kira-kira dapat diterima di lingkungan. Akantetapi mereka adalah pendengar yang baik, lebih menyukai lingkungan sosial dan peduli terhadap rekan kerja.

\section{Open Style}

Para atasan dengan gaya komunikasinya open style bersedia membagikan pengetahuannya sehingga mereka dapat menghasilkan solusi yang memuaskan kebutuhan semua pihak. Para atasan tipe ini juga paling baik dalam bernegoisasi terutama dalam resolusi konflik. Sehingga para bawahan yang ada masalah dalam pekerjaan bisa berkonsultasi dengan tipe atasan seperti ini karena mereka adalah orang yang jujur, bijaksana dan terbuka. Akantetapi karena gaya komunikasinya yang terlalu open bisa membuat orang merasa tidak terlalu nyaman.

Para bawahan dengan gaya komunikasinya yang open style biasanya merupakan karyawan yang puas akan lingkungan kerja dan organisasinya. Untuk bawahan tipe ini berikan pekerjaan dan tugas yang menantang serta berikan kritik dan pujian yang baik.

\section{KESIMPULAN DAN SARAN}

\section{Kesimpulan}

Communication Style mempengaruhi hubungan dengan atasan, bawahan, rekan kerja, dan tim dalam suatu organisasi. Masing-masing dari setiap orang memiliki Communication Style yang berbeda. Di penelitian ini membahas 4 gaya yang biasanya digunakan dalam komunikasi yaitu closed style, blind style, hidden style dan open style. Satu orang bisa saja mempunyai beberapa karakteristik dari keempat gaya, terkadang orang mepunyai satu atau dua karakterisitik yang lebih dominan. Jadi dari keempat communication style yang sudah dibahas dalam penelitian ini tidak ada gaya yang mana merupakan gaya baik atau buruk karena masing-masing memiliki sisi 
baik dan sisi buruknya. Yang perlu kita lakukan adalah terus menerus meningkatkan hubungan interpersonal agar komunikasi menjadi efektif.

\section{Saran}

Berdasarkan hasil penelitian, ada beberapa rekomendasi yang diberikan oleh peneliti yaitu :

1. Semua tingkatan organisasi mulai dari manager, supervisor dan staff harus mengetahui masing-masing communication style apa yang lebih dominan digunakan ketika berkomunikasi dengan orang lain. Hal ini membantu agar dapat meminimalisasi karakteristik yang negatif dalam setiap individu dan dapat meningkatkan hubungan interpersonal.

2. Penelitian ini dapat membantu membangun dan menjaga hubungan atasan dan bawahan agar tetap terjalin komunikasi yang baik. Jika diposisi atasan maka dapat mempelajari karakteristik dan mengetahui bagaimana menghadapi communication style dari para bawahannya agar divisinya mencapai tujuan yang diinginkan. Jika diposisi bawahan maka dapat mengetahui communication style mana yang merupakan communication style dari atasan sehingga dapat memenuhi harapan yang diinginkan oleh atasan dalam hal pekerjaan.

\section{Ucapan Terima Kasih}

Pada kesempatan ini, penulis ingin menyampaikan terima kasih kepada pihak yang telah memberikan bimbingan, dorongan dan semangat dalam penyusunan jurnal ini, yaitu kepada yang terhormat Ibu Dr. Riris Loisa, M.Si selaku Dosen mata kuliah Business Communication \& Interpersonal Skills yang berkenan untuk meluangkan waktu, tenaga dan pikiran dalam memberikan petunjuk, bimbingan dan pengarahan yang sangat bermanfaat kepada penulis dalam penyusunan jurnal ini.

\section{REFERENSI}

Alvonco, Johnson. (2014). Pratical Communication Skill. Penerbit: PT Elex Media Komputindo, Jakarta.

Daryanti. (2014). Teori Komunikasi. Penerbit: Gunung Samudera, Malang

Hamilton, Cheryl. (2011). Communicating for Results: A Guide for Business and the Professions, 9th ed. Boston: Wadsworth Cengage Learning

Keith Davis. (2009). Human Behavior at Work: Organizational Behavior. McGraw-Hill, New York.

Komala, Lukiati. (2009). Ilmu Komunikasi: Perspektif, Proses, dan Konteks. Widya Padjadjaran, Bandung

Nur Indiantoro \& Bambang Supomo. (2009). Metodologi Penelitian Bisnis Untuk Akuntansi \& Manajemen. BPFE, Yogyakarta.

Patricia, Obakpolo. (2015). "Improving Interpersonal Relationship in Workplaces". IOSR Journal of Research \& Method in Education. Educational administration, and policies studies, Delta State university Abraka delta state, Nigeria.

Sugiyono. (2010). Metode Penelitian Bisnis (Pendekatan Kuantitatif, Kualitatif dan R\&D). Penerbit Alfabeta, Bandung.

Tirtawinata, Christofora Megawati. (2013). "Mengenal dan Menemukan Diri melalui Kebersamaan dengan Orang Lain". Humaniora Vol.4 No 2. Binus University. 